\title{
Research on College Students' Color Preference
}

\author{
Guoquan Zhang \\ College of design and fashion engineering \\ Xiamen University of Technology \\ Xiamen, China
}

\begin{abstract}
Color preference of college students were investigated in this paper. 10 basic colors of Munsell color wheel were taken as the objects. 500 college students in Xiamen city were set as subjects. Preference value towards fashion colors were defined orderly from 10 to 1 . Minitab15 software was applied as the analyzing tool to analyze the data. Results showed that: 1) color preference of college students is ordered as: blue, purple, blue purple, red purple, blue green, red, green, yellow green, yellow and orange. 2) current college students prefer cold property colors.
\end{abstract}

Keywords-color preference; college students; young customers

\section{INTRODUCTION}

In the 21 st century, with the development of science and technology and the rapid extension of international information, the product similarity has impeded the brand competitiveness. The color is one of the elements of products. The color of product can enrich customers' understanding, adjust their emotions and influence people's working condition and change their behaviors and activities. According to an investigation of US fashion color research center, people only need seven seconds to determine whether they are interested in the commodities. During this period, the function of color accounts for $67 \%$ [1]. Color preference refers to customers' overall preference for color. It is a critical factor for customers to make decisions in purchase. Different consumer groups have different color preferences. Color researchers, research scholars of economics and anthropologists have researched the color preference of different consumer groups and achieved fruitful research results since 1920. [2-3] Many factors can affect customers' color preference: like customers' personal factors: age, sex, occupation, cultural background, nationality, the time, region, politics, and economic development. College students are very active among young customers. Their color preference is greatly influenced by the emotion, current events and fashion. Research on their color preference can provide important reference value for the color design of related products.

This research takes college students in Xiamen City as the object, the displayer as the carrier, 10 colors in the Munsell color wheel as the sample to discuss college students' color preference, including the following two problems: 1) Whether great differences in color preference exist between college students and ordinary young consumer groups, whether the color of product design for special consumer groups needs special orientation. 2) Whether the color preference of male and female college students at different grades is different and what the reasons are.

\section{RESEARCH METHODS}

\section{A. Test Object}

500 college students in Xiamen City are tested: including 250 male students and 250 female students without color blindness and color weakness.

\section{B. Experimental materials}

\section{1) Color selection}

10 colors in the Munshell color wheel are regarded as the sample color. The color number and the RGB value are shown in table 1. The saturation of tested color in the research is set as the maximum value.

TABLE 1 COLOR SAMPLE NUMBER AND ITS MUNSELL VALUE AND RGB VALUE

\begin{tabular}{llll}
\hline \multicolumn{1}{c}{ No. } & \multicolumn{1}{c}{ Color } & \multicolumn{1}{c}{ Munsell value } & \multicolumn{1}{c}{ RGB value } \\
\hline 1 & Red & $5 \mathrm{R} 5 / 18$ & $236,21,46$ \\
2 & Orange & $5 \mathrm{YR} 6.5 / 13$ & $233,118,13$ \\
3 & Yellow & $5 \mathrm{Y} 8.5 / 11$ & $243,205,34$ \\
4 & Yellow green & $5 \mathrm{GY} 8 / 12$ & $162,208,3$ \\
5 & Green & $5 \mathrm{G} 8 / 11$ & $31,222,146$ \\
6 & Blue green & $5 \mathrm{BG} 8 / 9$ & $40,217,198$ \\
7 & Blue & $5 \mathrm{~B} 7.5 / 9$ & $34,194,237$ \\
8 & Blue purple & $5 \mathrm{~PB} 6 / 14$ & $36,133,250$ \\
9 & Purple & $5 \mathrm{P} 5 / 26$ & $187,18,247$ \\
10 & Red purple & $5 \mathrm{RP5} 5 / 20$ & $253,24,139$ \\
\hline
\end{tabular}

2) Experimental samples

The color sample is showed on the displayer in square shape with the size of $3 * 3 \mathrm{~cm}$. The 10 colors is arranged in order of the color number and showed in two rows. The space between two colors is $1 \mathrm{~cm}$. The display background is neutral gray. The RGB values are 103, 103 and 103 respectively.

\section{3) Experimental method and step}

Experimental method: The color lumps are shown in the center of displayer. The test objects sit $30 \mathrm{~cm}$ away from the displayer. The height of their eyes is same as the height of horizontal symmetry line of the color lumps.

In the experiment, students first observe the colors shown in the displayer screen and grade the colors according to their feelings. Grade from one to ten points, 10 points for the favorite one and 1 point for the one they dislike most. The same point cannot appear in it. 


\section{4) Analysis tool}

The data are analyzed by Minitab 15 statistical analysis software in this experiment.

\section{RESUlT AND ANALYSIS}

\section{A. Color Preference Order}

The Minitab 15 statistical analysis software should be used to sum and sort the data. The total order of 500 college students' color preference is shown in table 2. The color preference is shown as the color mean value. For example, the mean value of college students' preference for color 3 is 6.4, showing the mean value of 500 students' preference for color 3 is 6.4 .

TABLE 2 ORDER OF COLLEGE STUDENTS' COLOR PREFERENCE

\begin{tabular}{cllllllllll}
\hline Order & 1 & 2 & 3 & 4 & 5 & 6 & 7 & 8 & 9 & 10 \\
\hline No. & 7 & 9 & 8 & 10 & 6 & 1 & 5 & 4 & 3 & 2 \\
$\begin{array}{c}\text { Mean } \\
\text { value }\end{array}$ & 6.8 & 6.4 & 6.4 & 5.8 & 5.6 & 5.3 & 5.2 & 5.1 & 5.0 & 4.7 \\
\hline
\end{tabular}

According to Table 2, the favorite color of college students is blue and the one they dislike most is orange. They prefer the cold colors. Colors including blue are popular among most people like: blue, blue purple and purple red. College students dislike the Chinese traditional folk colors like: yellow, orange and green. It has something in common and differences with the research results of Ge Liezhong in Zhejiang Sci-Tech University (Experiment Research on the Abstract Color Preference 2005) and Jie Shuiping in Jianghan University (Research on College Students' Preference in Clothing Color 2007). The analysis result of the former shows the order of college students' color preference is blue, red, orange, purple, yellow and green, and the order of color preference analyzed by the latter is blue, red, brown, purple, yellow, silver, orange and green. It shows the blue is people's favorite color at present. Different from the former research, the warm color of red ranks the second. For college students, the cold color of blue ranks the second.

According to the research results after the 1930s, [4, 6] most of Chinese college students taught by Zhou Xiangeng and Shen Naizhang like white and blue instead of purple and gray; the college students and middle school students taught by Zeng Hongwen like green most, and then the blue and dislike purple most. Although people's color preference changes with the time, it still has certain rules. Experimental materials and test methods adopted in different times are different, but the blue almost ranks first with the change of time. It has relationships with the continuous development of science and technology in today's world and the improvement of people's ecological environmental protection consciousness. People dislike the orange because it relates to the color of environmental sanitation. The result is obviously different from the traditional idea that the female prefer warm colors and the male prefer cold colors.

\section{B. Sex Differences}

The color preference values of the male and female are analyzed by the Minitab 15 statistical analysis software. The order of the male and the female college students' color preference is shown in Table 3.

TABLE 3 ORDER OF MALE AND FEMALE COLLEGE STUDENTS' COLOR PREFERENCE

\begin{tabular}{ccccccccccc}
\hline Order & & 2 & 3 & 4 & 5 & 6 & 7 & 8 & 9 & 10 \\
\hline Female & 7 & 9 & 8 & 10 & 6 & 1 & 5 & 4 & 3 & 2 \\
Male & 9 & 7 & 8 & 10 & 6 & 1 & 4 & 2 & 3 & 5 \\
\hline
\end{tabular}

Table 3 shows the color preference of the male and the female is not obviously different. The favorite color of the male is purple and that of the female is blue. Both of them have the obvious characteristic of blue. The color the male college students dislike most is green and that of the female college students dislike most is orange. The special connotation of green in the traditional culture influences the feelings of the male. In the order of color preference, both the male and the female prefer blue purple, red purple, blue green, red and yellow. The preferences of the male and the female for green and orange are different obviously: the female prefer green while the male dislike green most; the female dislike yellow most and it is also the most terrible color in the eyes of the male.

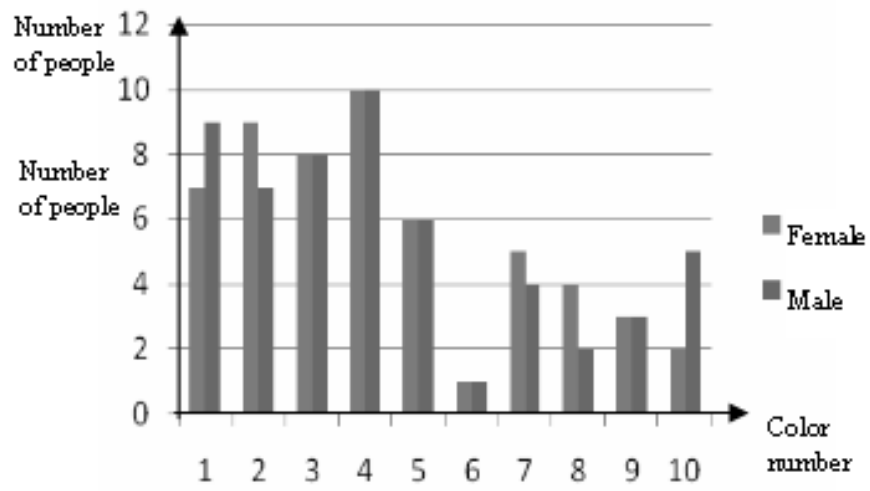

Fig. 1. Order of male and female college students' color preference

\section{Grade Difference}

The color preference values of students at different grades are analyzed by the Minitab 15 statistical analysis software. The order of color preference of college students at different grades is shown in table 3 . The figure 2 is the bar graph of color preference of students at different grades. 
TABLE 4 ORDER OF COLOR PREFERENCE OF STUDENTS AT DIFFERENT GRADES

\begin{tabular}{lllllllllll}
\hline Order & & & & & & & & & \\
\hline
\end{tabular}

According to table 4 and figure 2: Similarities exist in color preference of college students at different grades: they prefer blue, blue purple and purple and dislike orange, yellow, yellow green and green. They have different preferences for the color ranking the fourth and the seventh. For example, both freshman and senior dislike yellow (No. 3) most, while sophomore and junior show different preferences for yellow. Orange (No.2) is the most unpopular color for them. On the whole, the color preferences of college students at different grades are different in the warm colors and the cold colors.

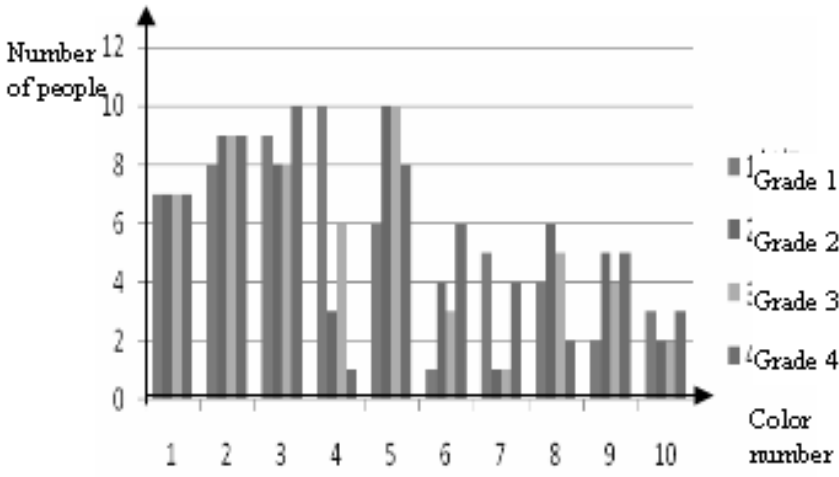

Figure 2 Comparison of color preference of students at different grades

The Minitab 15 is used to analyze the sex, grade and the variable of 10 color values. [7] Carry out the pairwise comparison through $\mathrm{S}-\mathrm{N}-\mathrm{K}$ method and compare the differences and interaction of color preference. Table 4 shows the differences and interaction of sex and grade in the variable score of orange V2. As shown in table 5, Sig. $=0.00<0.05$ in the grade variable shows the preferences of students at different grades for orange are greatly different. Sig. $=0.216>0.05$ in the sex shows the preferences of the male and the female are not different obviously. Comparing the score value of students at different grades, it shows the freshman gives the lowest mark for orange while the sophomore give the highest mark for it. The data in table 6 show interaction exists between grade and sex. Although the sophomore gives the highest mark for yellow, with the change of grade, the mark is more or less influenced by the sex. The difference in color preferences of sophomore, junior and senior is not obvious. It corresponds to the above analysis results.
TABle 5 Tests of BetweEn-SubJects EFFeCts（DEPENDENT VARIABLE: VAR2)

\begin{tabular}{llclcc}
\hline \multicolumn{1}{c}{ Source } & $\begin{array}{c}\text { Type III } \\
\text { Sum of } \\
\text { Squares }\end{array}$ & df & $\begin{array}{c}\text { Mean } \\
\text { Square }\end{array}$ & F & Sig. \\
\hline VARGRADE & 153.182 & 3 & 51.061 & 7.963 & .000 \\
VGENDER & 9.856 & 1 & 9.856 & 1.537 & .216 \\
VARGRADE $*$ & 70.644 & 3 & 23.548 & 3.672 & .012 \\
VGENDER & &
\end{tabular}

a R Squared $=.053$ (Adjusted R Squared $=.039$ )

TABLE 6 HOMOGENEOUS SubSETS

\begin{tabular}{lll}
\hline & Grade & \multicolumn{1}{c}{ Score $(\mathbf{x}+\mathbf{s d})$} \\
\hline 1 & $4.13707 \mathrm{a}$ \\
2 & $5.1310 \mathrm{~b}$ \\
3 & $4.8939 \mathrm{ab}$ \\
4 & $5.0357 \mathrm{ab}$ \\
\hline
\end{tabular}

Note: The difference is not obvious if the same letter exist on the top left corner. Otherwise, the difference is obvious.

\section{CONCLUSION}

A. College students prefer rational colors, namely the cold colors. The blue is most popular color among college students, so are the colors with blue tone.

B. The order of college students' color preference is: blue, purple, blue purple, red purple, blue green, red and green, yellow green, yellow and orange.

C. The preferences of the male and the female college students at different grades are different but not obviously.

\section{REFERENCES}

[1] Ellis L, Fricek C. Color preferences according to gender and sexual orientation $[\mathrm{J}]$ Personality Individual Differences, 2001, 31(8): 13751379 .

[2] Huang Xiting. Research on Chinese People's Color Sentiment [J] Psychological Science, $1991,14(6): 127$

[3] Ge Liezhong, Liu Shaoying, Xu Weidan. Experiment Research on the Abstract Color Preference [J], Psychological Science, 2005(4):849-851

[4] Jie Shuiping. Research on College Students' Preference in Clothing Color [J], Statistical Research, 2007(10):85-86

[5] Rupert Andrew Hurley;;Rachel Randall;:Liam O'Hara;;Charles Tonkin;;Julie C. Rice Color harmonies in packaging Color Res. Appl. 2017-1

[6] Ge Yan, Zhou Ronggang. Research on the Young Students' Color Preference for the Operation Interface of Computer [J], Chinese Journal of Ergonomics, 2004(3): 23

[7] Kazuhiko Yokosawa;Karen B. Schloss;;Michiko Asano;;Stephen E. PalmerEcological Effects in Cross - Cultural Differences Between U.S. and Japanese Color PreferencesCogn Sci 2016-7. 